\title{
TU/e emonownen

\section{Innovative impact assessment of electric vehicles charging loads on distribution transformers using real data}

Citation for published version (APA):

Godina, R., Rodrigues, E. M. G., Paterakis, N. G., Erdinç, O., \& Catalaõ, J. P. S. (2016). Innovative impact assessment of electric vehicles charging loads on distribution transformers using real data. Energy Conversion and Management, 120, 206-216. https://doi.org/10.1016/j.enconman.2016.04.087

\section{Document license:}

TAVERNE

DOI:

10.1016/j.enconman.2016.04.087

Document status and date:

Published: 15/07/2016

\section{Document Version:}

Publisher's PDF, also known as Version of Record (includes final page, issue and volume numbers)

\section{Please check the document version of this publication:}

- A submitted manuscript is the version of the article upon submission and before peer-review. There can be important differences between the submitted version and the official published version of record. People interested in the research are advised to contact the author for the final version of the publication, or visit the $\mathrm{DOI}$ to the publisher's website.

- The final author version and the galley proof are versions of the publication after peer review.

- The final published version features the final layout of the paper including the volume, issue and page numbers.

Link to publication

\section{General rights}

Copyright and moral rights for the publications made accessible in the public portal are retained by the authors and/or other copyright owners and it is a condition of accessing publications that users recognise and abide by the legal requirements associated with these rights.

- Users may download and print one copy of any publication from the public portal for the purpose of private study or research.

- You may not further distribute the material or use it for any profit-making activity or commercial gain

- You may freely distribute the URL identifying the publication in the public portal.

If the publication is distributed under the terms of Article 25fa of the Dutch Copyright Act, indicated by the "Taverne" license above, please follow below link for the End User Agreement:

www.tue.nl/taverne

Take down policy

If you believe that this document breaches copyright please contact us at:

openaccess@tue.nl

providing details and we will investigate your claim. 


\title{
Innovative impact assessment of electric vehicles charging loads on distribution transformers using real data
}

\author{
R. Godina ${ }^{\mathrm{a}}$, E.M.G. Rodrigues ${ }^{\mathrm{a}}$, N.G. Paterakis ${ }^{\mathrm{b}}$, O. Erdinc ${ }^{\mathrm{c}, \mathrm{d}}$, J.P.S. Catalão ${ }^{\mathrm{a}, \mathrm{d}, \mathrm{e}, *}$ \\ ${ }^{a}$ C-MAST, University of Beira Interior, R. Fonte do Lameiro, Covilhã 6201-001, Portugal \\ ${ }^{\mathrm{b}}$ Department of Electrical Engineering, Eindhoven University of Technology (TU/e), PO Box 513, 5600 MB Eindhoven, The Netherlands \\ ${ }^{\mathrm{c}}$ Department of Electrical Engineering, Yildiz Technical University, Davutpasa Campus, Esenler, 34220 Istanbul, Turkey \\ d INESC-ID, Instituto Superior Técnico, University of Lisbon, Av. Rovisco Pais, 1, Lisbon 1049-001, Portugal \\ ${ }^{\mathrm{e}}$ INESC TEC and the Faculty of Engineering of the University of Porto, $R$. Dr. Roberto Frias, Porto 4200-465, Portugal
}

\section{A R T I C L E I N F O}

\section{Article history:}

Received 2 February 2016

Received in revised form 15 April 2016

Accepted 24 April 2016

Available online 3 May 2016

\section{Keywords:}

Battery

Distribution transformer

EV charging

Loss-of-life

Transformer ageing

\begin{abstract}
A B S T R A C T
Widespread adoption of Electric Vehicles (EVs) could bring social and economic benefits. The effort of promoting the use of EVs in transportation is indispensable to meet the climate change related targets and to reduce the dependency on the ever unstable prices of diminishing fossil fuels. However, there are still many uncertainties in the market regarding the acceptability of EVs by the final consumers. As a new contribution with respect to earlier studies, this paper assesses the impact of EV charging load on the dielectric oil deterioration of two real Power Distribution Transformers (PDTs), one residential and one industrial, located in the insular grid of São Miguel. A PDT thermal model is used to estimate the hot-spot temperature given the load ratio. Real data are used for the main inputs of the model, namely, the daily residential load curve, the daily private industrial client load curve, the PDT parameters, time-of-use rates and EV parameters.
\end{abstract}

(c) 2016 Elsevier Ltd. All rights reserved.

\section{Introduction}

Concerns regarding urban air pollution, the climate change, and the dependency on unstable and costly supplies of fossil fuels have compelled policy makers and researchers to explore alternatives to conventional fossil-fuelled internal combustion engine vehicles. One such alternative is the introduction of Electric Vehicles (EVs) [1-3]. The broad adoption of such a means of transportation could signify a drastic reduction in greenhouse gases emissions and a compelling argument for the collective attempts to meet the emission mitigation goals [4-6]. As a result, during the last few years the electrification of transportation has been increasingly drawing attention.

The wide adoption of EVs is more challenging in comparison with the use of conventional and hybrid vehicles since the main energy source is electricity and therefore, the electric power systems should be qualified to accommodate new challenges and take advantage of the opportunities that are associated with the EV recharging load [7]. Moderate penetration levels might have a low impact on the grid. Nevertheless, as the number of EVs

* Corresponding author at: The Faculty of Engineering of the University of Porto, R. Dr. Roberto Frias, 4200-465 Porto, Portugal.

E-mail address: catalao@ubi.pt (J.P.S. Catalão). increases, a real possibility of the electric power systems being overloaded emerges - especially in the existing Distribution Network (DN) [8,9].

An event of a large number of EVs charging simultaneously can lead to grid inadequacy in terms of security and available network capacity. This situation can be averted in such cases where the EVs are appropriately incorporated into the electric power system. From the EVs point of view, an occasion of a high number of EVs charging at the same time could eventually be realistic [10]. Without a proper assimilation, the electric power system may possibly suffer excessive voltage drops, feeder congestion, etc., especially in the case of an isolated electrical grid, such as the one of São Miguel Island, Azores - a region that lacks a suitable plan for EV integration into the local electric power system.

The Smart Grid (SG) is defined as an electricity network that is capable of integrating in a smart way the actions of all users connected to it, with the intention to successfully distribute secure, economic, and sustainable electricity supplies [11]. The SG eases the accommodation of renewable energy resources (RES) that are distributed in nature into the present grid to support the mitigation of carbon emissions. The latest progress made by researchers in the SG field has led to the prediction of the connection of distributed RES and EVs to the power network and the various technical challenges that come from this new paradigm. Thus, the overcoming of such obstacles has to be done appropriately [12]. 


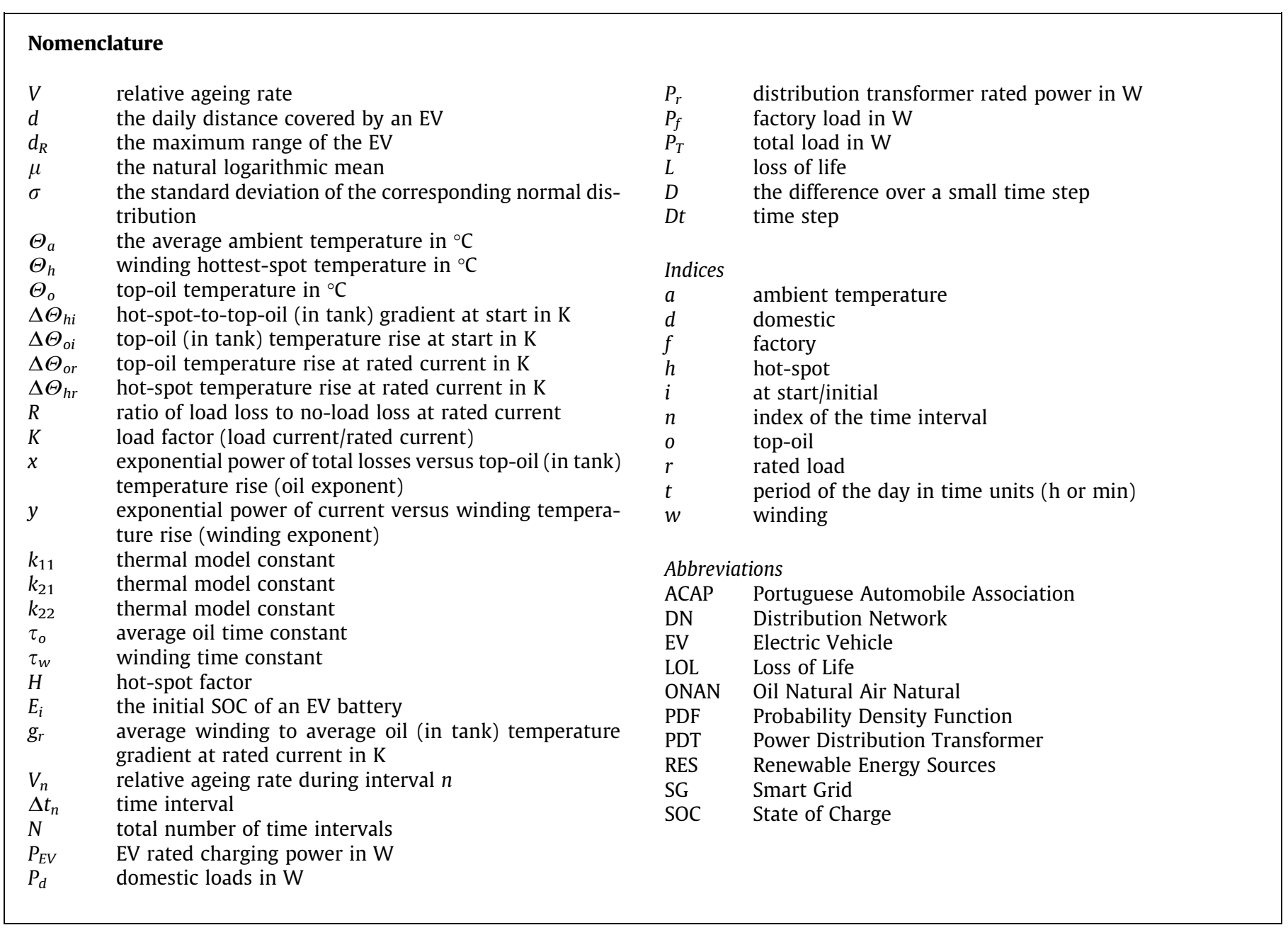

Recently, the implementation of SG enabling technologies in insular areas has been increasing rapidly, with the installation of diverse test systems in islands around the world. Even though the interconnected power system structure is deemed to be more rigid as regards stability, isolated areas which could offer an essential foundation for potential islanding operation requirements, could be seen as a perfect testing ground for the pre-evaluation of the SG paradigm [13].

The traditional DN is mainly designed as a passive network intended to deliver energy to the consumers [14]. Thus, there is the necessity to create and improve new models and methods with the purpose of assessing the impact that high penetration level of EV charging loads could have on the DN. This is also justified since there is a need to make sure that a high penetration of EVs does not overload the grid without reason, which ultimately adds to the existing efforts of reducing the environmental impact of human activity. Power Distribution Transformers (PDTs) are essential DN infrastructure that could suffer unparalleled charging loads due to the EVs. Several researchers investigated such themes, aiming to evaluate if the current existing electricity network and the PDT dielectric oil may resist to the penetration of EVs on a large scale [15-20]. In [15] the authors focused on identifying PDTs that are most vulnerable in cases of overloading as a result of the implementation of EVs through the employment of a binomial probability model that estimates the probability of a specific PDT to experience overloading. In [16] a study in which the effect of EVs charging on a local residential transformer by means of an Monte Carlo simulation that was utilized to foresee the final State of
Charge (SOC) of daily driving for a hybrid EV model and an EV model was performed. In [17] a method to assess the effect of EVs charging on overhead PDTs was described, also presenting a novel smart charging algorithm that regulates EV charging relying on the assessed PDTs temperatures. In another study [18] the way in which high penetration of EVs will influence the development of home energy management and PDT systems with the intention of decreasing the effect of EV battery charging on PDTs by using real load consumption data from Austin, Texas, was assessed. In [19] a model to investigate the effect of large scale penetration rates of additional power to restore the full level of EV battery SOC on the dielectric oil deterioration of PDTs through UK generic low voltage DN model was presented.

One of the most common elements that are found in DN is the PDT with an oil-immersed core. The DN of Azores uses almost exclusively oil-immersed PDTs - some of them upgraded very recently [21]. In addition to that, PDTs in their existing form are estimated to be the mainstream option for the years to come, due to their reliability and extensive use. Thus, the impact of specific SG practices such as EV charging on PDTs life and performance considerations must be evaluated in detail.

The contribution of this study is threefold:

- To present a model that allows the evaluation of the effect of EVs charging loads on the dielectric oil deterioration of two real PDTs, one supplying a residential area and the other a private industrial client, which in turn are part of the isolated electrical grid of São Miguel Island, Azores, Portugal. 
- To utilize a method that takes into account the uncertainty of EV battery charging loads, for instance the variability of the travel habits of the EV user before recharging - recorded in 2011, the battery SOC at the beginning of the charging process and different charging strategies.

- To study a particular case of an island with scenarios of high penetration of EVs and the EV charging at work during 3 different shifts considering an industrial load.

The remainder of the paper is organized as follows: in Section 2, the employed methodology is elaborated. In Section 3, the DN of São Miguel, Azores is presented and two cases are studied, one assessing the impact of EVs charging through the PDT of a residential area and another concerning an industrial client. Simulation results are also provided and discussed. Finally, conclusions are drawn in Section 4.

\section{Methodology}

\subsection{EV battery charging profiles}

The charging of EVs is an addition to the existing load. EVs are noticeably distinct when compared to other electrical loads, as a result of their highly mobile and unpredictable nature. Currently, three key factors that could affect the influence of EVs on DN exist, namely, the unique nature of the EV charging process, the driving profile and electrical energy tariff incentives.

With the growth of the EV market more and more car manufacturers enter the competition. Hence, a large number of EV types with different characteristics are available today [22]. As a result, in order to be more realistic, five different latest types of real EVs are used in this study - BMW i3, Renault ZOE, Ford Focus Electric, Nissan Leaf and Kia Soul [23-27].

In the last few years EVs are becoming technologically tempting due to the progress of Lithium-ion (Li-ion) battery technology that is capable of offering the advantage of higher power, as well as higher energy density. Given that Li-ion batteries are generally preferred as the main power source of the current EVs [28], in the present study it is implicitly considered that EVs in this case study employ such type of batteries. In fact, virtually all EVs that are available in the market today use this battery type due to its mature technology. The battery capacity for light vehicles in EVs is in the range of $6-35 \mathrm{~kW} \mathrm{~h}$. The charging time varies from $14 \mathrm{~h}$ for slow charging batteries to less than an hour for fast charging batteries [29].

All the EVs considered in this study employ Li-ion batteries and to understand better the effect of charging on the daily baseline load profile, the charging behaviour of a Li-ion battery is briefly described. While the SOC of the battery is low, the charger functions at its rated current, therefore it allows a great quantity of the battery SOC being re-established in the course of the initial charging hours. In practice, the process of charging a Li-ion battery, despite being represented by simplified characteristics, is described by a relation that reflects the mutually dependent occurrences of battery SOC and charger type [30]. The process pursues until the limit of the battery voltage is reached, at which the current falls while the EV charger preserves a constant voltage. The EV battery charging process is assumed to be continuous as soon as it is initiated until the full capacity of the battery is reached.

\subsection{Model of EV charging load}

In this paper and for both case studies the charging profile of $\mathrm{Li}$ ion EV batteries is utilized, and the stochastic behaviour of the EV battery SOC at the starting point of the charging process is calculated using a Probability Density Function (PDF) associated with the driving range as in [19,31]. The EV charging demand is given by the initial battery SOC, the charging start time and driving characteristics. Travel habits of the EV before the recharging process define the SOC at the beginning of the charging process of an EV battery and can be perceived as a random variable associated to the driving range. Using as a basis a study on the general travel information regarding Portuguese drivers of conventional vehicles recorded in 2011 in Lisbon area [32], a PDF of day-to-day driving range can be constructed as expressed by (1):

$$
(d ; \mu, \sigma)=\frac{1}{d \sqrt{2 \pi \sigma^{2}}} \times e^{-\frac{(\ln d-\mu)^{2}}{2 \sigma^{2}}}, d>0
$$

By knowing the average daily driving range, the SOC at the beginning of a recharge cycle, that is the residual battery capacity, is calculated utilizing (2), assuming that each trip is initiated with $100 \%$ SOC and that the SOC descents linearly during the course of the journey (2):

$E_{i}=\left(1-\frac{d}{d_{R}}\right) \times 100 \%$

A typical average value for travel distance is $100 \mathrm{~km} \mathrm{[33].}$

By replacing (2) into (1) and switching the variable from $d$ to $E$, and by succeeding the journey of one day, the PDF of the SOC of the battery is expressed as follows (3):

$h(E ; \mu, \sigma)=\frac{1}{d_{R}(1-E) \sqrt{2 \pi \sigma^{2}}} \times e^{-\frac{\left[\ln (1-E)-\left(\mu-\ln d_{R}\right)\right]^{2}}{2 \sigma^{2}}}, 0<E<1$

The PDF is truncated between $25 \%$ and $95 \%$ of battery SOC with parameters as in [34]. Since the equation is truncated at $25 \%$ and $95 \%$ of battery SOC it means that at the beginning of each charging process the battery can range from $25 \%$ to $95 \%$ of SOC depending on the travel habits of EV users. Consequently, EVs that are at, for example, $92 \%$ SOC - charge within minutes while the ones that are at, for instance, $26 \%$ will take hours to reach the full charge in the slow charging mode.

Based on the information drawn from both PDF, it is possible to estimate the residual battery capacity at the beginning of a recharge cycle. Both the electricity tariff rate structure and the objective of the use of the EVs by the users, which is an uncertain factor, influence the initial plug-in instance of the EV and the battery charging process.

\subsection{The loss of life of the PDT}

Since the PDT is a vital part of the DN, a proper conservation of mineral-oil-tilled PDTs is of a high importance in power systems and therefore, the necessity of implementing a caring methodology concerning PDT loading emerges [35].

The PDT insulation system is essentially created from paper and oil and both are subject to deterioration. Load intensification has an effect on the increase of the $\Theta_{h}$ and subsequently the thermal deterioration of the paper is affected [36-38].

As the distribution of the temperature is uneven, the most deteriorated section of the PDT will be the one with the highest temperature [39]. Thus, the $\Theta_{h}$ temperature directly affects the life duration of PDTs [19]. By definition, the $\Theta_{h}$ is the highest temperature of any spot in the PDT winding. By experiencing elevated electrical loads it originates high core-winding temperatures which in turn cause chemical breakdown of insulating oil and insulating paper [36,37]. 
2.3.1. Assessment of $\Theta_{h}$ temperature through exponential equations

In the case of ever-increasing steps of loads, $\Theta_{o}$ and winding $\Theta_{h}$ rise until a step equivalent to load factor $K$. As a consequence, equation of the top-oil $\Theta_{o}(t)$ temperature is shown in the following expression (4):

$$
\begin{aligned}
\Theta_{o}(t)= & \Delta \Theta_{o i}+\left\{\Delta \Theta_{o r} \times\left[\frac{1+R \times K^{2}}{1+R}\right]^{x}-\Delta \Theta_{o i}\right\} \\
& \times\left(1-e^{-t /\left(k_{11} \times \tau_{o}\right)}\right)
\end{aligned}
$$

The hot-spot temperature rise $\Delta \Theta_{h}(t)$ is as follows (5):

$$
\begin{aligned}
\Delta \Theta_{h}(t)= & \Delta \Theta_{h i}+\left\{H \times g_{r} \times K^{y}-\Delta \Theta_{h i}\right\} \\
& \times\left[k_{21} \times\left(1-e^{-t /\left(k_{22} \times \tau_{w}\right)}\right)-\left(k_{21}-1\right) \times\left(1-e^{-\left(t \times k_{22}\right) / \tau_{0}}\right)\right]
\end{aligned}
$$

For decreasing step of loads situations, the $\Theta_{o}$ and winding $\Theta_{h}$ are reduced until a step corresponding to a $K$ [36]. The equation of the top-oil temperature $\Theta_{o}(t)$ is expressed as following (6):

$$
\begin{aligned}
\Theta_{o}(t)= & \Delta \Theta_{o r} \times\left[\frac{1+R \times K^{2}}{1+R}\right]^{x} \\
& +\left\{\Delta \Theta_{o i}-\Delta \Theta_{o r} \times\left[\frac{1+R \times K^{2}}{1+R}\right]^{x}\right\} \times\left(e^{-t /\left(k_{11} \times \tau_{o}\right)}\right)
\end{aligned}
$$

The $\Theta_{h}$ increase is set by (7):

$$
\Delta \Theta_{h}(t)=H \times g_{r} \times K^{y}
$$

In conclusion, by taking into consideration $\Theta_{o}(t)$ and $\Delta \Theta_{h}(t)$ from (4) and (5) in case of increasing load steps, and (6) and (7) in case of decreasing load steps and by taking into account the ambient temperature $\Theta_{a}$ the complete hot-spot temperature $\Theta_{h}(t)$ expression is estimated as follows (8):

$\Theta_{h}(t)=\Theta_{a}+\Theta_{o}(t)+\Delta \Theta_{h}(t)$

2.3.2. Assessment of $\Theta_{h}$ temperature through differential equations

When heat-transfer principles are applied to the PDT situation, the differential equations for $\Theta_{o}$ (inputs $K, \Theta_{a}$ and output $\Theta_{o}$ ) is:

$$
\left[\frac{1+K^{2} R}{1+R}\right]^{x} \times\left(\Delta \Theta_{o r}\right)=k_{11} \tau_{o} \times \frac{d \Theta_{o}}{d t}+\left[\Theta_{o}-\Theta_{a}\right]
$$

The differential equation for $\Theta_{h}$ rise (inputs $K$ and output $\Delta \Theta_{h}$ ) is most easily solved as the sum of two differential equations where:

$\Delta \Theta_{h}=\Delta \Theta_{h 1}-\Delta \Theta_{h 2}$

The two equations are:

$k_{21} \times K^{y} \times\left(\Delta \Theta_{h r}\right)=k_{22} \times \tau_{w} \times \frac{d \Delta \Theta_{h 1}}{d t}+\Delta \Theta_{h 1}$

and

$\left(k_{21}-1\right) \times K^{y} \times\left(\Delta \Theta_{h r}\right)=\left(\tau_{o} / k_{22}\right) \times \frac{d \Delta \Theta_{h 2}}{d t}+\Delta \Theta_{h 2}$

the solutions of which are combined in accordance with Eq. (8). The final equation for the $\Theta_{h}$ is:

$\Theta_{h}=\Theta_{o}+\Delta \Theta_{h}$

If the differential equations are converted to difference equations, then the solution is quite straightforward, even using a simple spreadsheet. The differential equations (7)-(11) can be approximated by the following difference equations, where $D$ stands for a difference over a small time step. Eq. (7) becomes:
$D \Theta_{o}=D t / k_{11} \tau_{o}\left[\left[\frac{1+K^{2} R}{1+R}\right]^{x} \times\left(\Delta \Theta_{o r}\right)-\left[\Theta_{o}-\Theta_{a}\right]\right]$

The $D$ operator implies a difference in the associated variable that corresponds to each time step $D t$. At each time step, the $n^{\text {th }}$ value of $D \Theta_{o}$ is calculated from the $(n-1)^{\text {th }}$ value using:

$\Theta_{o(n)}=\Theta_{o(n-1)}+D \Theta_{o(n)}$

Eqs. (9) and (10) become:

$D \Delta \Theta_{h 1}=\frac{D t}{k_{22} \tau_{w}} \times\left[k_{21} \times \Delta \Theta_{h r} K^{y}-\Delta \Theta_{h 1}\right]$

and

$D \Delta \Theta_{h 2}=\frac{D t}{1 / k_{22} \tau_{o}} \times\left[\left(k_{21}-1\right) \times \Delta \Theta_{h r} K^{y}-\Delta \Theta_{h 2}\right]$

The $n^{\text {th }}$ values of each of $\Delta \Theta_{h 1}$ and $\Delta \Theta_{h 2}$ are calculated in a way similar to Eq. (13). The total $\Theta_{h}$ rise at the $n^{\text {th }}$ time step is given by:

$\Delta \Theta_{h(n)}=\Delta \Theta_{h 1(n)}+\Delta \Theta_{h 2(n)}$

Finally, the $\Theta_{h}$ temperature at the $n^{\text {th }}$ time step is given by:

$\Theta_{h(n)}=\Theta_{o(n)}+\Delta \Theta_{h(n)}$

\subsubsection{The PDT calculation of loss of life}

In case of the thermally upgraded paper the equation of the ageing rate $V$ is expressed as follows [37]:

$V=e^{\left(\frac{15000}{110+273}-\frac{15000}{\theta_{h}+273}\right)}$

The ageing rate $V$ [37] corresponds to the deterioration of paper insulation at a temperature $\Theta_{h}$ which is higher or lower than $110^{\circ} \mathrm{C}$, with respect to the ageing rate at $110^{\circ} \mathrm{C}$ [36]. The Loss of Life (LOL) of cellulose insulation which calculated using the differential equations can also be expressed with difference equations. The fundamental differential equation is:

$\frac{d L}{d t}=V$

implying:

$D L_{(n)}=V_{(n)} \times D t$

and:

$L_{(n)}=L_{(n-1)}+D L_{(n)}$

The LOL equation $L$ can also be rewritten and for the duration of the time segment $t_{n}$ is expressed as following:

$L=\int_{t_{1}}^{t_{2}} V d t$ or $L \approx \sum_{n=1}^{N} V_{n} \times t_{n}$

\section{Simulation results}

\subsection{The PDT proprieties}

In order to determine transient solutions for $\Theta_{o}$ and $\Theta_{h}$ a thermal model is developed and proposed for the PDT and can be applied to both three-phase and to single-phase PDTs.

The PDT power rating and cooling system is provided by the insular Distribution System Operator (DSO). The properties of both PDTs used in this paper are obtained from Ravetta et al. [40] that presented the data of a real 250 and $630 \mathrm{kVA}\left(P_{r}\right)$ oil PDTs with Oil Natural Air Natural (ONAN) cooling where a natural 
convectional flow of hot oil is utilized for cooling. The constants are taken from [36]. Both PDTs properties are drawn from $[41,42]$.

\subsection{Structural elements of the insular grid}

The Azores are a Portuguese autonomous region and a 9 island archipelago located in the North Atlantic, circa $3900 \mathrm{~km}$ from the east coast of North America. São Miguel Island is the capital and most populated island. The island has around 140,000 inhabitants and covers an area of $760 \mathrm{~km}^{2}$. In this paper, a part of São Miguel medium voltage DN is investigated.

The research presented in this paper focuses on two different cases in which the evaluation of the effect of EVs charging loads on the dielectric oil deterioration of two real oil-immersed PDTs, one supplying a residential area and the other a private industrial client, which are referred to as case study 1 and 2, respectively. The starting time of charging EVs is selected by taking into account the daily habits of São Miguel's people and the off-peak tariff. In this regard, data are provided under SiNGULAR project [43].

Two different percentages of EVs are used for the two different cases under investigation. The percentage of BMW i3 is chosen in both case studies as high as $40 \%$ since it is the fastest selling EV in Portugal according to the Portuguese Automobile Association (Associação Automóvel de Portugal - ACAP) [44]. Renault ZOE and Ford are selected to have a $20 \%$ market penetration since these brands already appear to have a significant share in the conventional vehicle market [44]. Data for the charging types and duration of the five EVs are presented in [41] for the first case study and for [42] the second case study.

The present market outlook of EVs can be considered globally low, not exceeding a $7 \%$ share in leading countries such as Norway [19]. On the other hand, in this paper, very high penetration levels are examined. Particularly for an insular area, such as São Miguel, the relatively high transportation cost of fossil fuels, the presence of rich potential of RES, and the opportunities that emerge from the efficient management of an EV fleet [13], are factors that have led the authors to believe that the penetration levels that are likely to be met in such areas in the future will be significantly higher than in continental areas. In addition, supporting initiatives of governments frequently have a tendency to aim specific areas such as islands and as a result, potential funding programs or tax reduction schemes to endorse the acquisition and use of EVs are highly expected to significantly encourage customers to exchange their fossil-fuelled internal combustion engine vehicles with EVs [45].

\subsection{Case study 1}

For this case study a PDT that supplies a residential area is chosen. The part of the medium voltage DN and an identification of several outputs can be found in [41]. The PDT substation PT80 which supplies 292 households through a $630 \mathrm{kVA}, 10 \mathrm{kV} / 0.4 \mathrm{kV}$ oil-immersed PDT is used.

During the summer of 2014 a number of measurements were performed at the PDT substation PT80 and the energy consumption of 292 households registered. Plus, the daily temperature records for the aforementioned period are shown in Fig. 1. The baseline load profile is withdrawn from [41]. It may be observed that a $630 \mathrm{kVA}$ PDT is oversized for a $140 \mathrm{~kW}$ of peak in daily baseline load profile, even if in Azores higher consumption is witnessed during the summer [21].

The EV load demand can be affected to some extent by the electricity tariff structure. For this model the current electricity tariff of Azores Islands that entered into force in 2015 is taken into account. Even though a three rate tariff for domestic consumers currently exists in Azores, for this study the two rate tariff is used. The off- peak tariff is $190 \%$ lower than the peak tariff and it is initiated instantly after 22:00 [46].

Based on the data collected from the PDF it is possible to apply the PDT thermal model, using the load ratio as an input to obtain the $\Theta_{h}$ and $\Theta_{o}$. For this case study one day and a half of the baseline load profile of the summer period of the PDT substation PT80 is used.

The total load (in $\mathrm{kW}$ ) on the PDT is the summation of the $n_{d}$ domestic loads $P_{d}$ and loading from $n_{E V}$ randomly selected EVs:

$P(t)=\left|n_{d} P_{d}(t)+\sum_{E V=1}^{n_{E V}} P_{E V}(t)\right|$

A fitting algorithm is applied to assess the impact of EVs charging loads on the dielectric oil deterioration of PDT based on the previously presented methodology. The charging of EV batteries inflicts an extra load on the PDT. By hypothesizing that a PDT supplies several EVs in a neighbourhood, different charging time and load profiles are obtained for the PDT. The algorithm integrates data obtained from the PDF and calculates the $\Theta_{h}$ and the PDT LOL due to EVs charging loads.

Two different scenarios are studied, the first being with different initial SOC of the EVs based on the PDF function, plus different penetration ratios of EVs are considered in this study for the household neighbourhood, beginning with $75 \%$ penetration and then with $80 \%, 85 \%, 90 \%, 95 \%$ and $100 \%$. Also, it is considered that $50 \%$ of the EV owners charge their cars in slow charging mode and the other $50 \%$ in domestic fast charging mode since the model can be applied for both. Finally, it is assumed that 55\% of EVs begin charging at 22:00 or are scheduled to do so since as seen before, for Azores the off-peak tariff is $190 \%$ lower than peak tariff and it becomes available exactly at 22:00 of each day, as for the remaining $45 \%$ of EVs, it is assumed that these users are not very concerned with off-peak tariffs and that the EVs charging are set to begin at 07:00 or are scheduled to do so, when users wake up and go to work and the slow charging mode is used after home arrival, usually after 18:00. These specific percentages are chosen as such due to the reason of being just under and/or above the PDT loading limit, other percentages are redundant.

The second scenario explores a case where during the weekend and at the rule of the same off-peak tariff all the EVs are scheduled or the users choose to charge or the EVs are set to charge at 22:00 and all the owners charge their cars in slow charging mode. The impact on the daily baseline load profile of the PDT substation PT80 made by the energy consumption of the EVs at several penetration ratios from both scenarios is shown in Fig. 2 and in Fig. 4, respectively, where (hh:mm) signifies the time in hours and minutes. The starting times of charging for the first scenario is chosen due to the fact that EV users typically do not have a need for fast recharging since they dispose of sufficient time - 3-8 h (depending on the charge level) during the non-working period of the day or after 22:00 at the residence with the intention of skipping the drawback of recurring to a public charging station.

By analysing Figs. 2 and 4 it can be concluded that for a penetration of EVs of more than 75\% the PDT is overloaded. It is then possible to assess the PDT insulation ageing affected by the $\Theta_{h}$ and the LOL of the PDT which is presented in Figs. 3 and 5, respectively.

Using the ageing equations (20) and (24), the LOL of the PDT can now be determined. The LOL of the PDT is presented in percentage and also in hours and minutes for each day of EV charging which means that from the PDT expected life at $0 \%$ penetration $(180,000 \mathrm{~h})$ a number of hours for each day of charging is withdrawn. The results can be seen in Table 1 .

From Figs. 2-5 and from Table 1 it can be concluded that the off-peak tariff will encourage users to prefer a certain hour of charging, in this case, 22:00, that will cause a concentration of EVs charging at the same time which in turn will generate an over- 


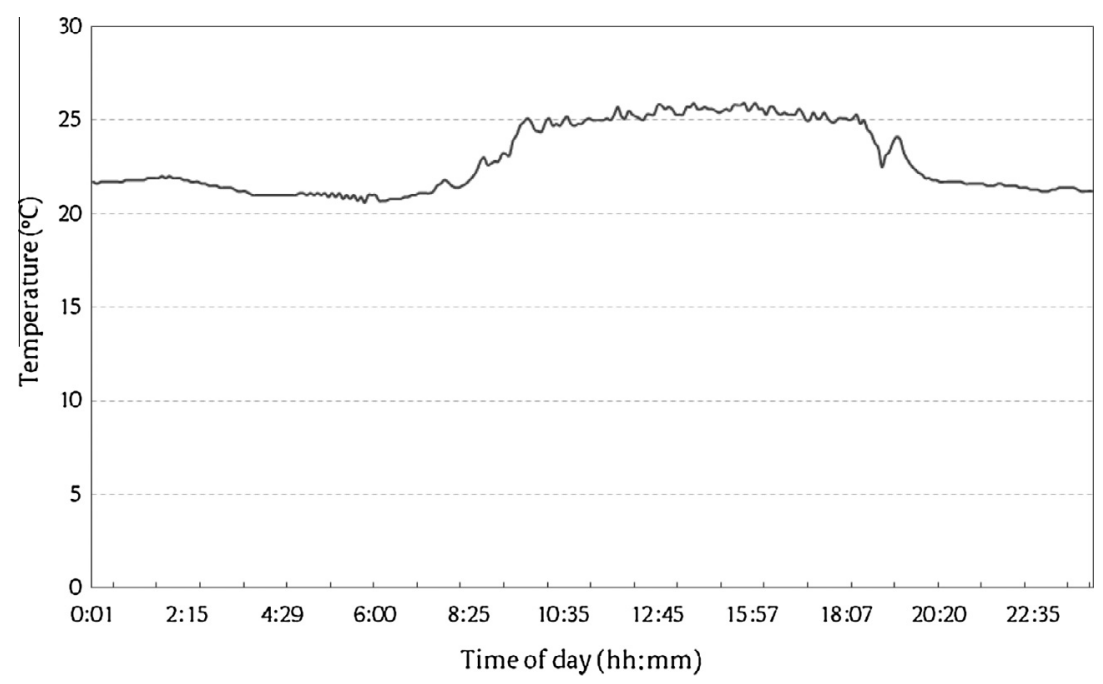

Fig. 1. Temperature of a typical summer day in São Miguel.

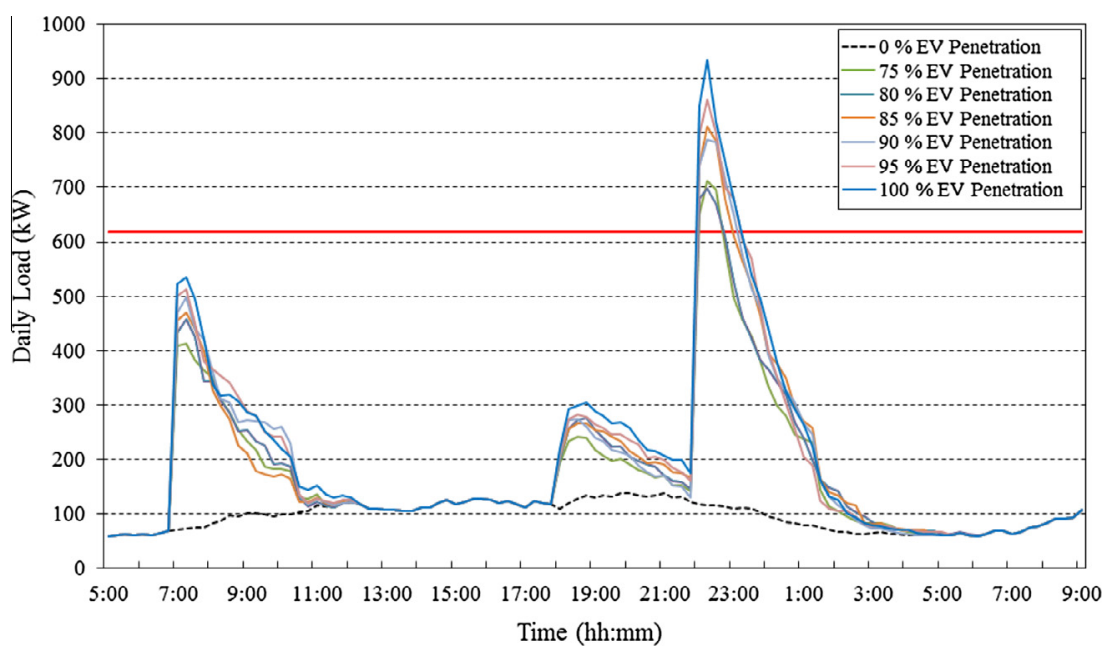

Fig. 2. The daily baseload profile (case 1 , scenario 1 ).

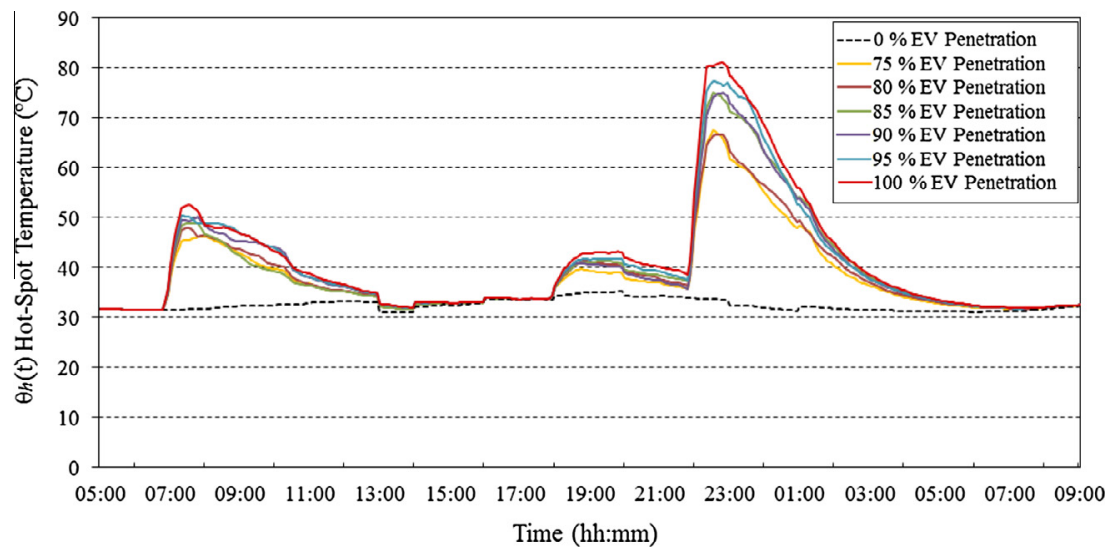

Fig. 3. The $\Theta_{h}$ of the PDT (case 1, scenario 1)

loading of the PDT, a sudden increase of the $\Theta_{h}$ and consequently will affect the PDT lifetime.

In both scenarios it can be concluded that for more than $75 \%$ of EV penetration the PDT will be overloaded resulting in a growth of the $\Theta_{h}$ of the PDT. The LOL increases with the increase of EV penetration in both scenarios.

By analysing the results obtained from Table 1 it can be concluded that the PDT LOL is only affected after a certain level of 


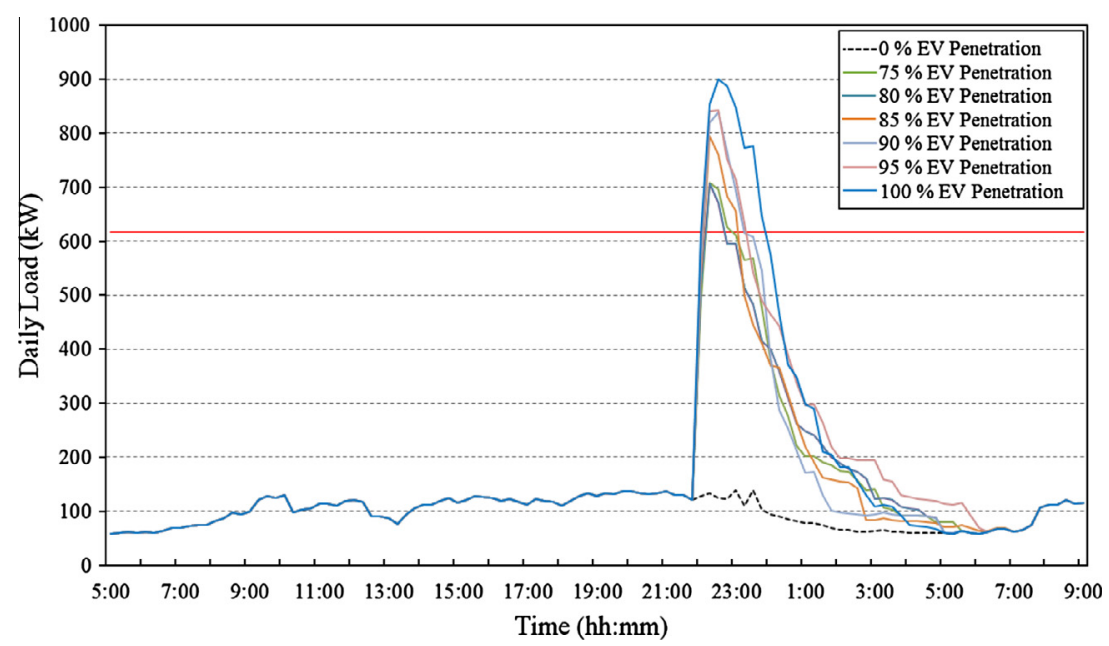

Fig. 4. The daily baseload profile (case 1, scenario 2).

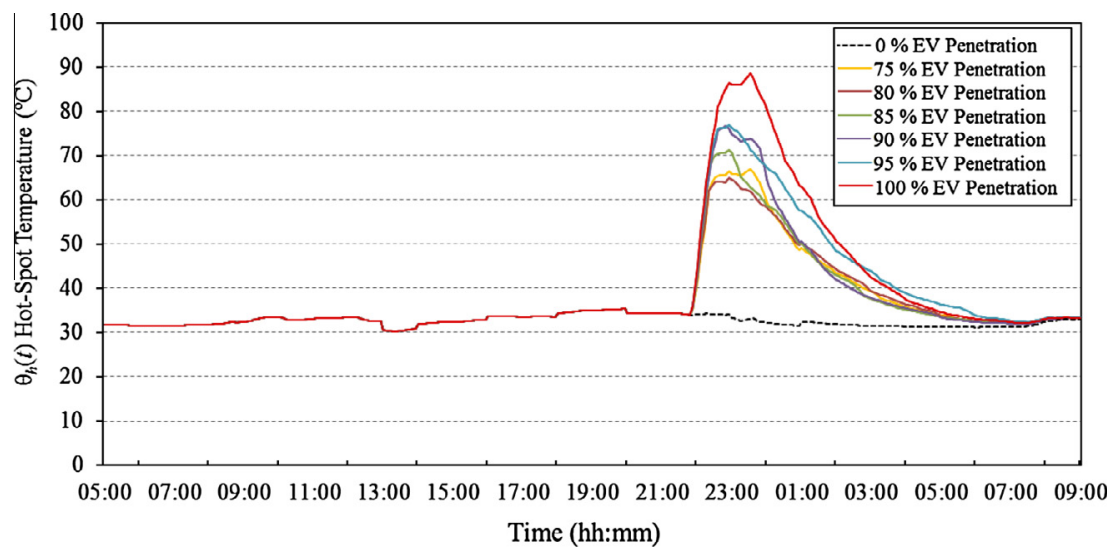

Fig. 5. The $\Theta_{h}$ of the PDT (case 1, scenario 2).

Table 1

Daily transformer LOL due to EV charging (case 1).

\begin{tabular}{llllll}
\hline \multirow{2}{*}{ Level of penetration (\%) } & \multicolumn{2}{l}{ Scenario 1} & & \multicolumn{2}{l}{ Scenario 2} \\
\cline { 2 - 3 } \cline { 6 - 7 } & LOL & \% LOL & & LOL & \% LOL \\
\hline 0 & $0 \mathrm{~h} 00 \mathrm{~m}$ & 0 & & $0 \mathrm{~h} 00 \mathrm{~m}$ & 0 \\
75 & $0 \mathrm{~h} 50 \mathrm{~m}$ & 0.0005 & & $0 \mathrm{~h} 38 \mathrm{~m}$ & 0.00035 \\
80 & $1 \mathrm{~h} 09 \mathrm{~m}$ & 0.0006 & & $0 \mathrm{~h} 46 \mathrm{~m}$ & 0.0004 \\
85 & $1 \mathrm{~h} 23 \mathrm{~m}$ & 0.0008 & & $0 \mathrm{~h} 54 \mathrm{~m}$ & 0.0005 \\
90 & $1 \mathrm{~h} 41 \mathrm{~m}$ & 0.0009 & & $1 \mathrm{~h} 06 \mathrm{~m}$ & 0.0006 \\
95 & $2 \mathrm{~h} 17 \mathrm{~m}$ & 0.0013 & & $1 \mathrm{~h} 24 \mathrm{~m}$ & 0.0008 \\
100 & $2 \mathrm{~h} 50 \mathrm{~m}$ & 0.0016 & & $2 \mathrm{~h} 46 \mathrm{~m}$ & 0.0015 \\
\hline
\end{tabular}

EV penetration, which is relatively high. If the EV users keep this profile of charging every day, the PDT will have a deteriorating LOL after some time.

\subsection{Case study 2}

This case focuses on a PDT that supplies a private industrial client. A part of the medium voltage DN and an identification of several outputs can be seen in [42].

In this case study the PDT substation PT1094 which supplies one private industrial client through a $250 \mathrm{kVA}, 10 \mathrm{kV} / 0.4 \mathrm{kV}$ oilimmersed PDT is used.

The private industrial client is a factory that produces sugar out of sugar beet. It employs 120 workers and operates in 3 working shifts of $8 \mathrm{~h}$ each. The first working shift starts at 08:00, the second at 16:00 and the third at 00:00. It is assumed in this paper that the workers are evenly distributed throughout the working shifts.

During the summer of 2014 several measurements were made at the PDT substation PT1094 and the energy consumption of the industrial client was recorded and as a consequence, a daily baseline load profile is generated and can be observed in [42]. It is also given the power factor of the PDT is approximately 0.95 . It may be observed that a $250 \mathrm{kVA}$ PDT is properly sized for a $140 \mathrm{~kW}$ of peak in daily baseline load profile, considering that a typical value for an inferior size PDT would be $167 \mathrm{kVA}$ which is not adequate [21].

The total load $P(t)$ (in $\mathrm{kW}$ ) on the PDT is the sum of the factory load $P_{f}(t)$ and loading from $n_{E V}$ randomly selected EVs:

$P(t)=\left|P_{f}(t)+\sum_{E V=1}^{n_{E V}} P_{E V}(t)\right|$

For this case study one day of the baseline load profile of the summer period of the PDT substation PT1094 is used and two different scenarios are examined.

\subsubsection{Scenario 1}

For the first scenario different penetration ratios of EVs for each working shift are considered for this industrial client, starting at $35 \%$ and reaching up to $55 \%$. The number of EVs in this case can be calculated simply by dividing the 120 employees by 3 shifts, 


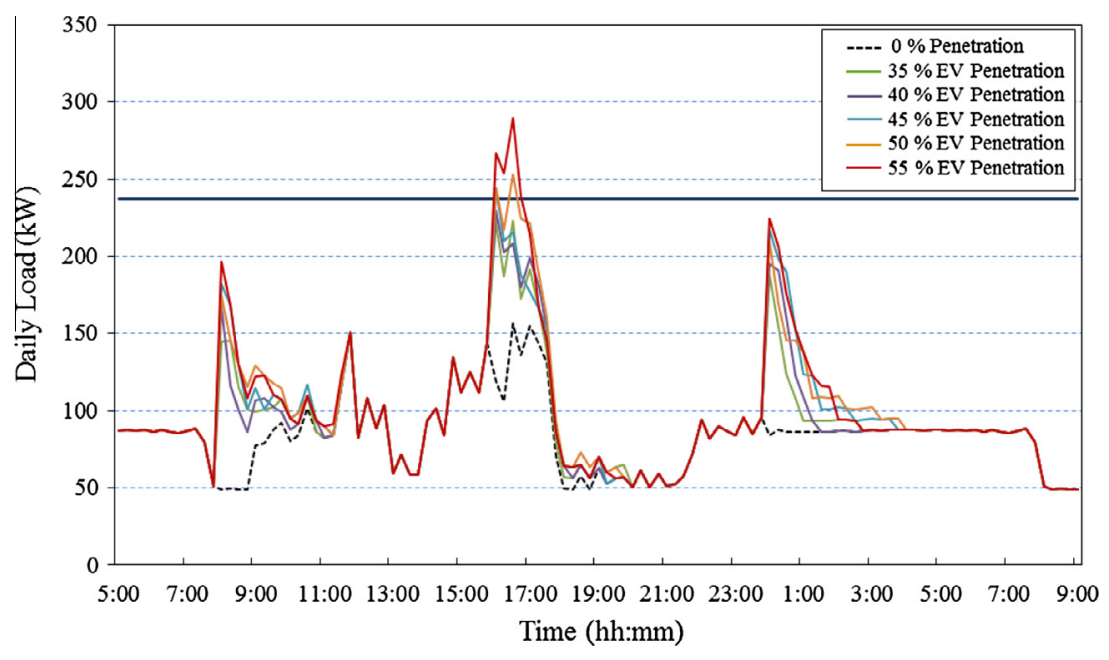

Fig. 6. The daily baseload profile (case 2, scenario 1).

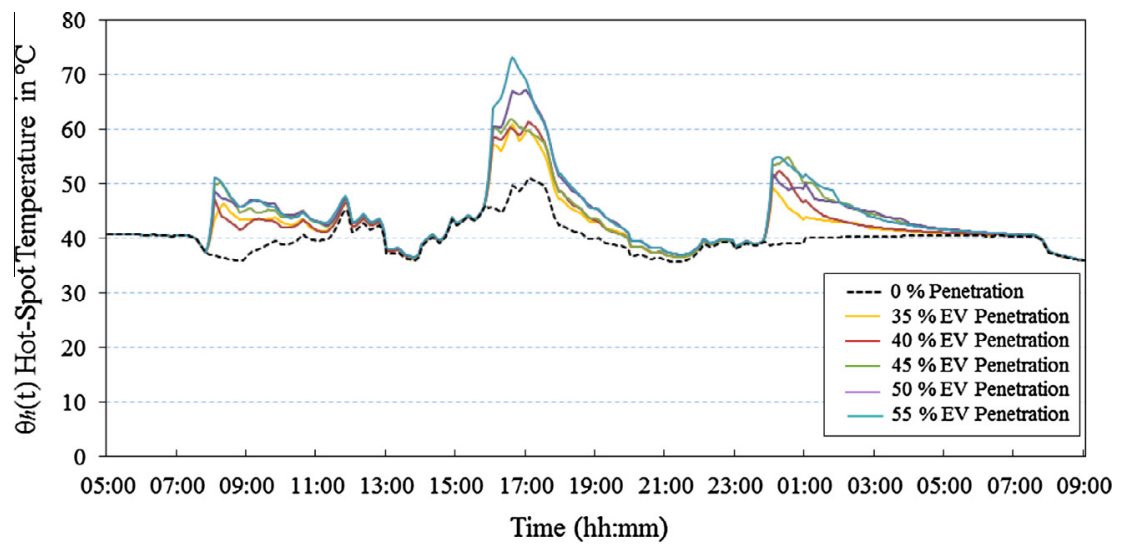

Fig. 7. The $\Theta_{h}$ of the PDT (case 2, scenario 1).

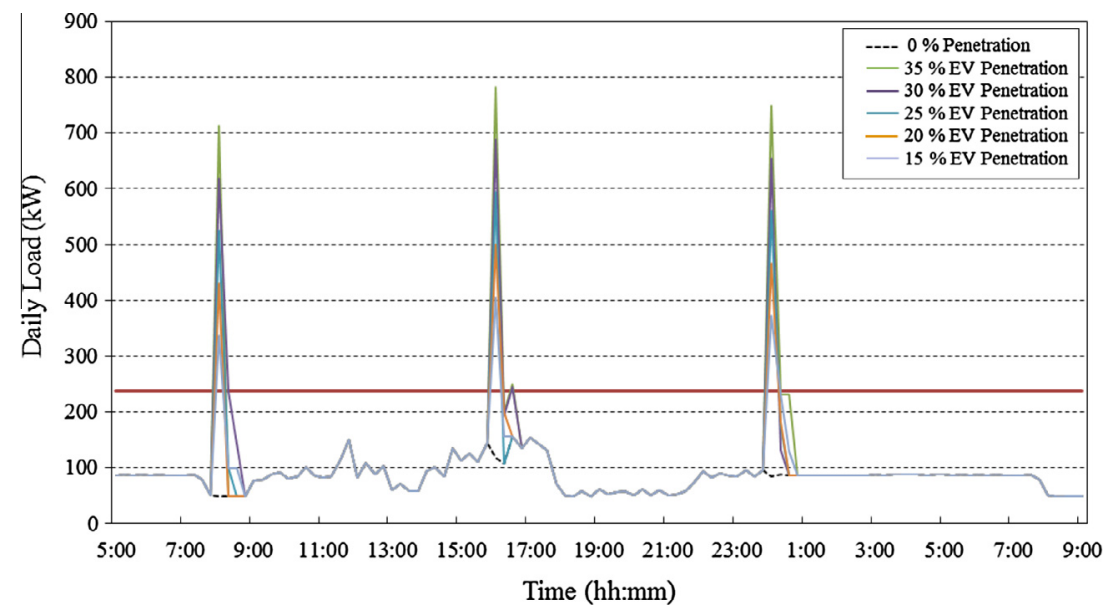

Fig. 8. The daily baseload profile (case 2, scenario 2).

resulting in 40 workers per shift. Thus, for instance, $50 \%$ of EVs translates in 20 EVs charging per shift. These specific percentages are chosen as such due to the reason of being just under and/or above the PDT loading limit, other percentages are redundant.
Finally it is assumed that the EVs start or are scheduled to charge at the beginning of each working shift.

The effect on the daily baseline load profile of the PDT substation PT1094 created by the energy consumption of the EVs at several 


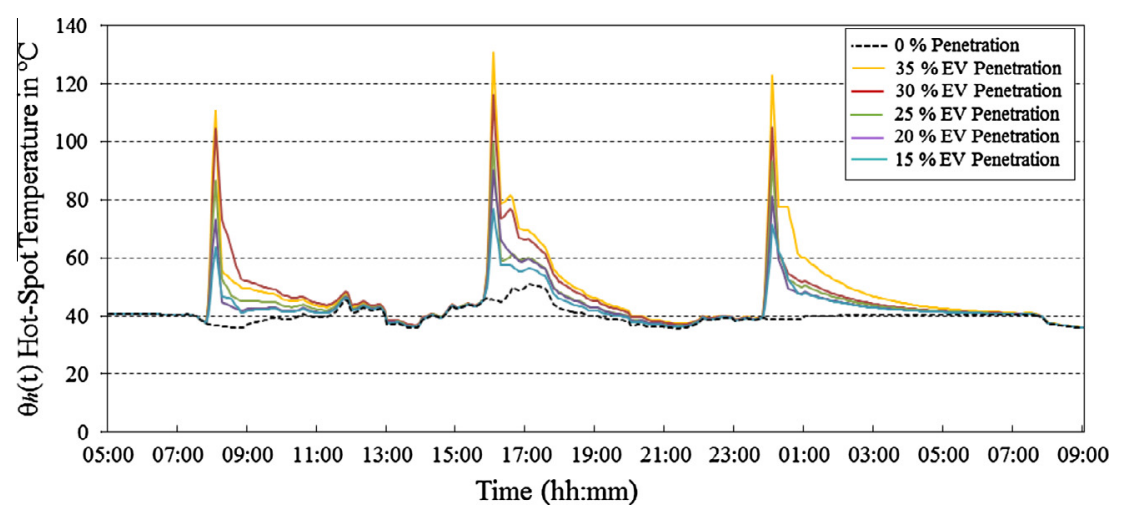

Fig. 9. The $\Theta_{h}$ of the PDT (case 2, scenario 2).

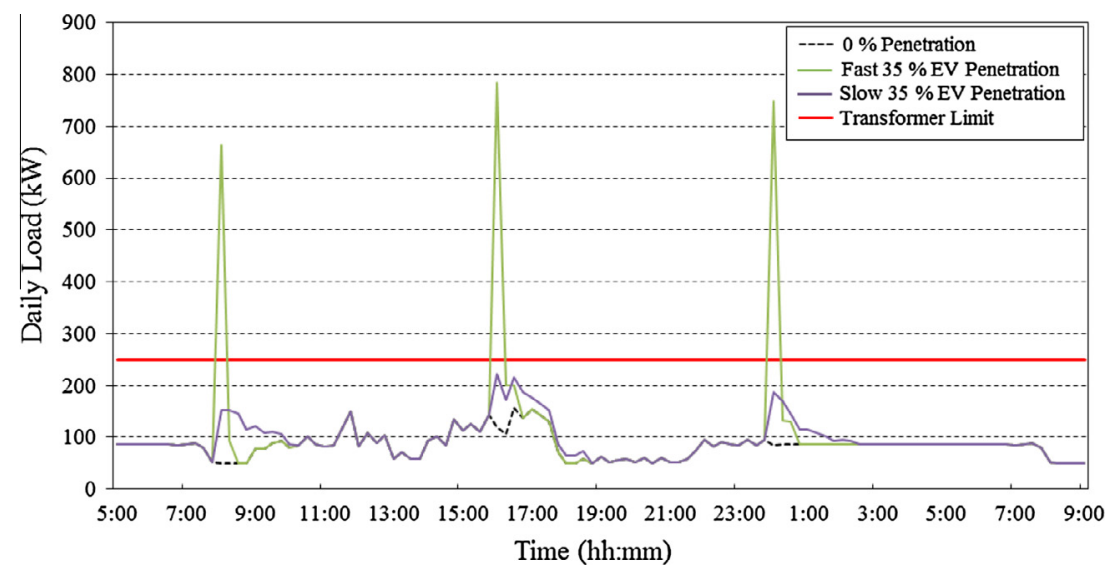

Fig. 10. Comparison between scenario 1 and 2 of the daily baseload profile in case 2 .

Table 2

Daily transformer LOL due to EV charging (case 2).

\begin{tabular}{|c|c|c|c|c|c|}
\hline \multicolumn{3}{|l|}{ Scenario 1} & \multicolumn{3}{|l|}{ Scenario 2} \\
\hline EV penetration (\%) & $\operatorname{LOL}(\mathrm{t})$ & LOL \% & EV penetration (\%) & $\operatorname{LOL}(\mathrm{t})$ & LOL \% \\
\hline 35 & $0 \mathrm{~h} 36 \mathrm{~min}$ & 0.0003 & 15 & $0 \mathrm{~h} 58 \mathrm{~m}$ & 0.0005 \\
\hline 40 & $0 \mathrm{~h} 40 \mathrm{~min}$ & 0.0004 & 20 & $1 \mathrm{~h} 22 \mathrm{~m}$ & 0.0004 \\
\hline 45 & $0 \mathrm{~h} 45 \mathrm{~min}$ & 0.0004 & 25 & $4 \mathrm{~h} 23 \mathrm{~m}$ & 0.0024 \\
\hline 50 & $0 \mathrm{~h} 58 \mathrm{~min}$ & 0.0005 & 30 & $16 \mathrm{~h} 02 \mathrm{~m}$ & 0.0089 \\
\hline 55 & $0 \mathrm{~h} 77 \mathrm{~min}$ & 0.0007 & 35 & $70 \mathrm{~h} 22 \mathrm{~m}$ & 0.0391 \\
\hline
\end{tabular}

penetration ratios from the first scenario is shown in Fig. 6. The daily baseline load profile is also shown as $0 \%$ penetration ratio.

By analysing Fig. 6 it can be observed that for a penetration of EVs of more than $40 \%$ the PDT is overloaded. Also, from the information obtained from the model and presented in Fig. 6, it is possible to assess the PDT insulation ageing affected by the $\Theta_{h}$ which is presented in Fig. 7 and subsequently to calculate LOL at the designated penetration ratios of the PDT. The LOL of the PDT is presented in percentage and in hours and minutes for each day of EV charging which means that from the PDT expected life at $0 \%$ penetration the number of minutes or hours for each day of charging is subtracted. The results can be seen in the Table 2 .

\subsubsection{Scenario 2}

The second scenario is defined as follows: all EVs are charged with fast charging mode considering penetration levels of $15 \%$,
$20 \%, 25 \%, 30 \%$, and $35 \%$. The percentages are set as in the first scenario in order to observe the differences between slow and fast charging modes. Just as in the previous scenario, it is assumed that the workers put their EVs to charge at the beginning of each working shift.

The impact on the daily baseline load profile of the PDT substation PT1094 induced by the energy consumption of the EVs at several penetration ratios from the second scenario is shown in Fig. 8.

By observing Fig. 8 it can be noticed that for a penetration of EVs of more than $15 \%$ the PDT is profoundly overloaded even for low penetration levels. Also, from the information presented in Fig. 8, the PDT insulation ageing can be assed for this scenario. The relevant results are depicted in Fig. 9. By means of the ageing equations (5) and (6), the LOL of the PDT can now be determined. The results can also be seen in Table 2 . 


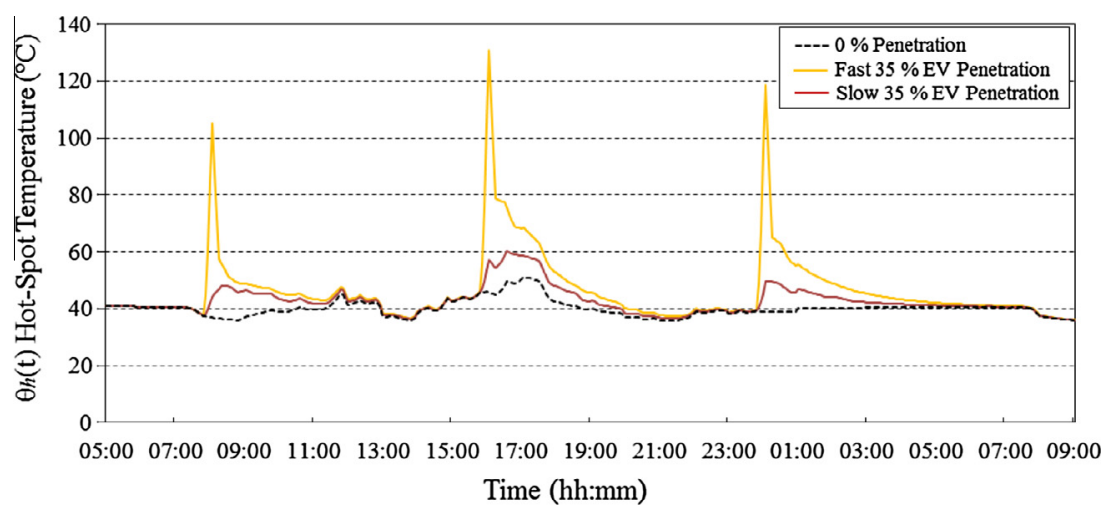

Fig. 11. Comparison between scenario 1 and 2 of the $\Theta_{h}$ of the PDT in case 2 .

\subsubsection{Critical analysis}

By analysing the results obtained from Table 2, it can be concluded that the PDT LOL is only affected after a certain amount of EV penetration which is relatively high. If the EV users make such profile of charging a routine the PDT will have a deteriorating LOL after some time.

The comparison of both scenarios at $35 \% \mathrm{EV}$ penetration in Figs. 10 and 11 highlights the level of impact on the PDT ageing by using fast charging over slow charging. By analysing Figs. 6-9 and Table 2 it can be concluded that each beginning of a shift will influence users to prefer the first hour of charging, that will originate a concentration of EVs charging at the same time, which in turn could cause an overloading of the PDT, a sudden increase of the $\Theta_{h}$ and thus will affect the PDT lifetime.

By observing the results of first scenario it can be deduced that for more than $40 \%$ of EV penetration the PDT will be overloaded resulting in an increase of the $\Theta_{h}$ of the PDT. The LOL slightly increases with the increase of EV penetration in this scenario.

In the improbable event of the second scenario occurring, the LOL of the distribution PDT is significantly higher. Thus, it is advised to avoid the fast charging mode when charging EVs at work, since the slow mode takes at maximum $5 \mathrm{~h}$ which is always less than a working shift of $8 \mathrm{~h}$.

\section{Conclusions}

In this paper a model to estimate the influence of simultaneous EV charging on the dielectric oil deterioration of two PDTs, one at a residential area and other at a private industrial client, was applied. Two different case studies were examined, one focusing on a residential area during working days and weekends and another concerning a private industrial client with several penetration ratios at three different working shifts. The power rating of both PDTs and the cooling system were provided by the local DSO. Since the PDT insulation ageing is mainly affected by the $\Theta_{h}$ and by knowing the load ratio a PDT thermal model was utilized to calculate the $\Theta_{h}$. The main inputs to the model, including residential load, PDT parameters, and five different vehicle parameters were taken from real data. Dielectric oil deterioration was then calculated and analysed. Since both PDTs have a significant capacity to be used for a side activity, this study shows that they can still be overloaded after a certain level of EV penetration. The developed methodology was applied to assess the impact of multiple EVs charging in the same residential area and it showed that off peak tariff can have an influence over EV users and affect the PDT lifetime. The results show that the LOL of the PDT is only affected after a certain amount of EV penetration, which is relatively high. In both case studies the penetration ratios that reach the limit of the transformer were studied; thus, if the penetration of the EVs increase from these scenarios onward then accelerated deterioration of the oil is expected. The second case study showed also that while charging at the workplace, the slow charging mode was recommended over the fast mode. Even if the slow charging mode was selected by the users the vehicles will always be $100 \%$ charged at the end of each working shift and without drastically affecting the PDT lifetime when compared to the fast charging mode.

\section{Acknowledgements}

This work was supported by FEDER funds (European Union) through COMPETE and by Portuguese funds through FCT, under FCOMP-01-0124-FEDER-020282 (Ref. PTDC/EEA-EEL/118519/2010), UID/CEC/50021/2013 and SFRH/BPD/103744/2014. The research leading to these results has also received funding from the EU Seventh Framework Programme FP7/2007-2013 under Grant agreement No. 309048. Also, the work of N.G. Paterakis received financial support from the Smart Grid Evolution project (project number TESG113013), funded under TKI Switch2SmartGrids, a research programme funded by RVO, an agency of the Ministry of Economic Affairs, The Netherlands.

\section{References}

[1] Hackbarth A, Madlener R. Willingness-to-pay for alternative fuel vehicle characteristics: a stated choice study for Germany. Transport Res Part A: Policy Pract 2016;85:89-111.

[2] Morais H, Sousa T, Soares J, Faria P, Vale Z. Distributed energy resources management using plug-in hybrid electric vehicles as a fuel-shifting demand response resource. Energy Convers Manage 2015;97:78-93.

[3] Torreglosa JP, García-Triviño P, Fernández-Ramirez LM, Jurado F. Decentralized energy management strategy based on predictive controllers for a medium voltage direct current photovoltaic electric vehicle charging station. Energy Convers Manage 2016;108:1-13.

[4] Jochem P, Babrowski S, Fichtner W. Assessing $\mathrm{CO}_{2}$ emissions of electric vehicles in Germany in 2030. Transport Res Part A: Policy Pract 2015;78:68-83.

[5] Schuller A. Charging coordination paradigms of electric vehicles. In: Plug in electric vehicles in smart grids. Singapore: Springer; 2015. p. 1-21.

[6] Khazali A, Kalantar M. A stochastic-probabilistic energy and reserve market clearing scheme for smart power systems with plug-in electrical vehicles. Energy Convers Manage 2015;105:1046-58.

[7] Duan Z, Gutierrez B, Wang L. Forecasting plug-in electric vehicle sales and the diurnal recharging load curve. IEEE Trans Smart Grid 2014:5(1):527-35.

[8] Richardson P, Flynn D, Keane A. Optimal charging of electric vehicles in lowvoltage distribution systems. IEEE Trans Power Syst 2012;27(1):268-79.

[9] Haidar AM, Muttaqi KM, Sutanto D. Technical challenges for electric power industries due to grid-integrated electric vehicles in low voltage distributions: a review. Energy Convers Manage 2014;86:689-700.

[10] Das R, Thirugnanam K, Kumar P, Lavudiya R, Singh M. Mathematical modeling for economic evaluation of electric vehicle to smart grid interaction. IEEE Trans Smart Grid 2014;5(2):712-21.

[11] Shayeghi H, Ghasemi A, Moradzadeh M, Nooshyar M. Simultaneous day-ahead forecasting of electricity price and load in smart grids. Energy Convers Manage 2015;95:371-84.

[12] Malik FH, Lehtonen M. A review: agents in smart grids. Electric Power Syst Res 2016;131:71-9. 
[13] Erdinc O, Catalao J, Uzunoglu M, Rifat Boynuegri A, Smart insular grids: opportunities and challenges. In: 2013 third international conference on electric power and energy conversion systems (EPECS), Istanbul; 2013.

[14] Jazebi S, Hosseinian S, Vahidi B. DSTATCOM allocation in distribution networks considering reconfiguration using differential evolution algorithm. Energy Convers Manage 2011;52(7):2777-83.

[15] Sexauer J, McBee K, Bloch K. Applications of probability model to analyze the effects of electric vehicle chargers on distribution transformers. IEEE Trans Power Syst 2015;28(2):847-54.

[16] Gong Q, Midlam-Mohler S, Marano V, Rizzoni G. Study of PEV charging on residential distribution transformer life. IEEE Trans Smart Grid 2012;3 (1):404-12.

[17] Hilshey A, Hines P, Rezaei P, Dowds J. Estimating the impact of electric vehicle smart charging on distribution transformer aging. IEEE Trans Smart Grid 2013;4(2):905-13.

[18] Vicini R, Micheloud O, Kumar H, Kwasinski A. Transformer and home energy management systems to lessen electrical vehicle impact on the grid. IET Gener Transm Distrib 2012;6(12):1202-8.

[19] Oian K, Zhou C, Yuan Y. Impacts of high penetration level of fully electric vehicles charging loads on the thermal ageing of power transformers. Int J Electr Power Energy Syst 2015;65:102-12.

[20] Gong Q, Midlam-Mohler S, Serra E, Marano V, Rizzoni G. PEV charging control considering transformer life and experimental validation of a $25 \mathrm{kVA}$ distribution transformer. IEEE Trans Smart Grid 2015;6(2):648-56.

[21] EDA S.A. - Electricidade dos Açores. Caracterização Das Redes De Transporte E Distribuição De Energia Eléctrica Da Região Autónoma Dos Açores. Ponta Delgada; 2014

[22] Young K, Wang C, Wang LY, Strunz K. Chapter 2 - Electric vehicle battery technologies. In: Electric vehicle integration into modern power networks. New York: Springer; 2013. p. 15-56.

[23] Bayerische Motoren Werke. The new BMW i3 - launches November 2013. BMW UK, Printed in the UK; 2013.

[24] Kia Motors Europe. The new Kia. Frankfurt am Main, Germany: Kia Motors Europe.

[25] Renault SA. Renault ZOE simply revolutionary. Renault U.K. Limited Customer Relations, The Rivers Office Park, Denham Way, Maple Cross, Rickmansworth, Hertfordshire; 2013.

[26] (c)2014 Nissan North America Inc. 2014 nissan leaf brochure. Dealer E-Process; 2014.

[27] Ford Motor Company. 2014 ford focus electric brochure. Ford Motor Company; 2013.

[28] Castano S, Gauchia L, Voncila E, Sanz J. Dynamical modeling procedure of a Liion battery pack suitable for real-time applications. Energy Convers Manage 2015:92:396-405.

[29] Haidar A, Muttaqi K, Haque M. Multistage time-variant electric vehicle load modelling for capturing accurate electric vehicle behaviour and electric vehicle impact on electricity distribution grids. IET Gener Transm Distrib 2015;9(16):2705-16.
[30] Pinto F, Costa L, Dias de Amorini, MF, Costa L, Dias de Amorini M. Modeling spare capacity reuse in EV charging stations based on the Li-ion battery profile. In: 2014 International conference on connected vehicles and expo (ICCVE), Vienna; 2014.

[31] Zhang P, Qian K, Zhou C, Stewart B, Hepburn D. A methodology for optimization of power systems demand due to electric vehicle charging load. IEEE Trans Power Syst 2012;27(3):1628-36.

[32] Pereira NBRC. MSc thesis - Eficiência energética no sector dos transportes rodoviários: metodologia para quantificação do excesso de energia consumida devido ao factor comportamental na condução de veículos automóveis ligeiros. Lisbon: Departamento de Ciências e Tecnologia da Biomassa Universidade Nova de Lisboa; 2011.

[33] Qian K, Zhou C, Allan M, Yuan Y. Modeling of load demand due to EV battery charging in distribution systems. IEEE Trans Power Syst 2011;26(2):802-10.

[34] Vagropoulos SI, Bakirtzis AG. Optimal bidding strategy for electric vehicle aggregators in electricity markets. IEEE Trans Power Syst 2013:28(4):4031-41.

[35] Georgilakis PS. Environmental cost of distribution transformer losses. Appl Energy 2011;88(9):3146-55.

36] IEC 60076-7. Loading guide for oil-immersed power transformers; 2005

[37] C57.91-2011. IEEE guide for loading mineral-oil-immersed transformers and step-voltage regulators. IEEE Standard; 2012

[38] Pezeshki H, Wolfs P, Ledwich G. Impact of high PV penetration on distribution transformer insulation life. IEEE Trans Power Deliv 2014:29(3):1212-20.

[39] Godina R, Rodrigues EMG, Matias JCO, Catalão JPS. Effect of loads and other key factors on oil-transformer ageing: sustainability benefits and challenges Energies 2015;8(10):12147-86.

[40] Ravetta C, Samanna' M, Stucchi A, Bossi A. Thermal behavior of distribution transformers in summertime and severe loading conditions. In: 19th international conference on electricity distribution, Vienna; 2007.

[41] Godina R, Paterakis N, Erdinc O, Rodrigues E, Catalão J. Electric vehicles home charging impact on a distribution transformer in a Portuguese island. In: 2015 International symposium on smart electric distribution systems and technologies-EDST 2015, Vienna; 2015.

[42] Godina R, Paterakis N, Erdinc O, Rodrigues E, Catalão J. Impact of EV chargingat-work on an industrial client distribution transformer in a Portuguese island. In: Proceedings of the 25th Australasian Universities power engineering conference-AUPEC 2015, Wollongong; 2015.

[43] SiNGULAR. Smart and sustainable insular electricity grids under large-scale renewable integration. Grant Agreement No: 309048, FP7-EU; 2015. Available: <http://www.singular-fp7.eu/home/> [Accessed 2015].

[44] ACAP. Associação Automóvel de Portugal. Available: <http://www.acap.pt/pt/ home> [Accessed 2002 2015].

[45] Erdinc O, Paterakis NG. Chapter 1 - Overview of insular power systems: challenges and opportunities. Smart and sustainable power systems: operations, planning and economics of insular electricity grids. Boca Raton, Florida: CRC Press (Taylor \& Francis Group); 2015. p. 1-34.

[46] EDA S.A. - Electricidade dos Açores. Preçário 2015 das Tarifas da Região Autónoma dos Açores. Ponta Delgada: EDA - Electricidade dos Açores; 2015. 